\title{
TRACKING OF LEARNING LEVEL ON DESIGN AND SAFETY SKILLS IN TWO CORE SUBJECTS OF THE CHEMICAL ENGINEERING DEGREE AT UPV
}

\author{
B. García-Fayos, M. Sancho, J.M. Arnal \\ Chemical and Nuclear Eng. Department, Universitat Politècnica de València (SPAIN)
}

\begin{abstract}
Chemical engineers develop their profession in areas in which design of processes and safety of installations, equipment and procedures designed are especially relevant due to the impact and consequences that a failure of these items represent. Therefore, curriculum of chemical engineers chemical engineering should include these disciplines as a valuable skill. In the Universitat Politècnica of València (UPV), design and safety competence training is worked in the curriculum of chemical engineering degree through several subjects. "Experimentation in Chemical Engineering III" (Elq3) from $3^{\text {rd }}$ course, semester B and "Industrial Processes of Chemical Engineering" (PIIQ) from $4^{\text {th }}$ course semester A, are core courses specially focussed on the development of several activities to work these skills.

In Elq3 students design a production process to obtain oil from almond for cosmetic purposes. This design project includes: lab work to study and understand the stages of the production process and its performance, drawing of block and flow diagram of the process by using Autocad and recommendation of basic safety measures in the installation. In the following semester, students of PIIQ study different production processes and design a process to obtain olive oil. This design includes drawing of block and flow diagram of the full process, selection and justification of safety measures needed and its implementation in the installation through its drawing in the flow diagram. Safety is also strengthened through an activity of safety presentation about an item related to the installation that students should prepare and defense.
\end{abstract}

This work collects and analyses the evolution of the learning level and its deepness into safety and design skills through the analysis of the results obtained along the several control points stablished in Elq3 and PIIQ courses. These control points are: deliverables of academic works at the beginning of Elq3, assessment of design project and written exam at the end of Elq3 and academic results at the end of PIIQ of several academic years.

Progressive work along these two consecutive courses in safety and design skills have allowed to obtain a deeper degree of learning in these disciplines and better results in a medium term compared with the previous academic years in which these activities and methodology were not performed in both subjects.

Keywords: Design, safety, chemical engineering, process.

\section{INTRODUCTION}

Chemical engineers develop their profession in areas in which design of processes and safety of installations, equipment and procedures designed are especially relevant due to the impact and consequences that a failure of these items represent. Therefore, curriculum of chemical engineers should include these disciplines as a valuable skills.

There is a common agreement in considering that teaching this disciplines should be compulsory in all courses of Chemical Engineering [1-2] as a tool to prevent accidents and in response to the significant role that the chemical engineer has to prevent and reduce the risk associated with accidents that may occur in a chemical plants or industrial activity designed [3-4].

To reach a deep learning in these disciplines, teaching-learning process should be considered not as a complement of the teaching in industrial processes but as an integral part of the curriculum of engineering [5]. 
In the last years, adaptation to the European higher education area has resulted in the creation of new official degrees at Bachelor and Master level in Spanish universities. This process has been focused on enhancing training in competences (understood as a "know how" complex) and involves the learning, not only of knowledge but also skills and attitudes in order allow students the development of their profession in a successful, autonomous and accountable way. In these degrees, we find generic, specific and cross-curricular competencies. The last ones, are considered for many institutions a tool for differentiation in the labor market of graduates with respect to others who obtain the same degree at another university. In addition, national and international accreditation agencies such as the Accreditation Board for Engineering and Technology (ABET) or by the European Network for Accreditation of Engineering Education (ENAEE) consider these competencies as an indicator of quality of the University studies that they assess. These competences should be worked through specific activities included in the subjects, linked to learning outcomes and assessed to analyze the degree of acquisition by the students throughout their studies.

The Universitat Politècnica de València (UPV), has an institutional project that defines 13 transversal competences (TC) in which students are trained [6] and which comply with the requirements of ABET and ENAEE agencies. In them, "design and project" competence is included as TC-5.

In the case of the Chemical engineering degree at UPV, the implementation of TC was conducted during the 2015-2016, by assigning each cross-curricular competence to one or several subjects referred to as control points. TC-5 training is worked in the curriculum of chemical engineering degree through several subjects. "Experimentation in Chemical Engineering III" (Elq3) from $3^{\text {rd }}$ course, semester B and "Industrial Processes of Chemical Engineering" (PIIQ) from $4^{\text {th }}$ course semester A, are core courses specially focussed on the development of several activities to work these skills.

This paper will describe the activities developed in both subjects to work TC- 5 and analyses the evolution of the learning level reached at the end of PIIQ, which is the last course where this competence is worked.

\section{CONTEXT AND COURSE DESCRIPTION}

"Process of Chemical Engineering" (PIIQ), is a compulsory subject in the fourth year, with 4.5 ECTS credits, in the Chemical Engineering degree at UPV. The average group size has been 75 students from 2013-2014 till present academic year.

The teaching of this course began in the academic year 2013-2014, and their descriptors based on the Verification memorandum included description of industrial processes but also process layout, safety, auxiliary facilities, water conditioning, environmental management, wastes, graphical representation of processes, materials selection, matter and energy balance, petrochemical industry and risk analysis.

In spite of previous learning teaching of safety is considered a base of chemical engineers training, this was not included as a previous compulsory subject in the academic curriculum, so students arrived to PIIQ without basic concepts about this matter. This situation forced to include safety skills in the subject. Several approaches were made to find an active methodology that made students to acquire basic skills on this competence. Methodology included: guided practice classroom (2013-2014 and 2014-2015), cooperative learning through case of study (2015-2016) [7] and cooperative learning through case of study combined with research group methodology in the last academic years (20162017, 2017-2018 and 2018-2019 with satisfactory results [8].

This approach has reinforced in parallel with the development in the previous experimental subjects of an innovative pedagogical project awarded by the UPV Educational Science Institute (ICE) called "Integration of safety skills through experimental subjects of Chemical engineering degree" (ISES) performed in the academic year 2012-2013 in Experimentation in Chemical Engineering I, II and III. Table 1 explains the evolution of safety integration skills over the core courses of the chemical engineering degree. 
Table 1. Progressive introduction of safety skills formation through ISES project on core courses of Chemical Engineering degree at UPV

\begin{tabular}{|c|c|c|c|c|}
\hline \multicolumn{4}{|c|}{ Course } & \multirow{3}{*}{ Methodology for Safety in PIIQ } \\
\hline EIQI & EIQII & EIQIII & PIIQ & \\
\hline \multicolumn{4}{|c|}{ Academic year } & \\
\hline & & $2012-2013$ & 2013-2014 & Guided practice classroom \\
\hline & $2012-2013$ & 2013-2014 & $2014-2015$ & Guided practice classroom \\
\hline $2012-2013$ & $2013-2014$ & 2014-2015 & 2015-2016 & Cooperative learning through case of study \\
\hline 2013-2014 & $2014-2015$ & 2015-2016 & 2016-2017 & $\begin{array}{l}\text { Cooperative learning through case of study + } \\
\text { research group methodology }\end{array}$ \\
\hline
\end{tabular}

As it is shown in the table, in 2012-2013 ISES project has introduced in the academic curriculum of the chemical engineering degree. Students that were attending to EIQIII received basic formation about this topic that was complemented by the contents introduced by PIIQ in 2013-2014. Students that were attending to EIQII in 2012-2013, could deep in safety skills in two experimental courses before arriving to PIIQ in the academic year 2014-2015. Only from academic course 2015-2016 and the followings, all the students that arrived to PIIQ had been received previous formation on safety skills through 3 previous experimental subjects. That was the reason to change methodology into cooperative learning through case of study which requires previous knowledge about this matter to solve the proposed activities. In 2016-2017 small modifications were performed to combine cooperative learning through case of study and research group methodology that has been kept until present academic year.

With respect to Design skills, there are several courses in the curriculum of the Chemical engineer at UPV that are working to develop this competence but in an isolated way, without linking different aspects of the chemical engineering profession as graphical representation, cost analysis, material selection, mass and energy balance calculations, equipment selection, etc... Due to experimentation in the laboratory provides a very appropriate framework to carry out the implementation and development of design skills because students are in contact with experiments and equipment that can be translated to a real design, it was considered to develop a Design project in the Elq3 course using the Project Oriented Learning (POL) approach [9]. This change was also performed in the context of an innovative pedagogical project awarded by the UPV Educational Science Institute, called "Integration of POL in an experimental subject of Chemical engineering degree" (IPOL) that was initiated in the academic year 2016-2017 in the Elq3 subject.

"Experimentation in Chemical Engineering III" (Elq3) is a $3^{\text {rd }}$ course, semester B subject of 4.5 ECTS credits. The subject has two blocks, one for the Design and other for Simulation purposes. In the design block, students use laboratory sessions to obtain information that will use in the design project. After each session they deliver an academic work about the experimental session that lecturer checks and gives back to students in order to give them feed-back about the information collected and calculations performed that will be used in the design stage. In parallel to laboratory sessions, students have to develop a design project based on solid-liquid extraction, in groups, under the supervision of the lecturer.

Students should design a production process to obtain oil from almond for cosmetic purposes. This design project includes: lab work to study and understand the stages of the production process and its performance, drawing of block and flow diagram of the process (by using preferably Autocad) and recommendation of basic safety measures in the installation. This approach allows student to integrate the knowledge acquired in different subjects in a practical way through an installation design, analogously to what they will have to do in their professional lives as engineers.

An example of the design asked is shown in Figure 1. 

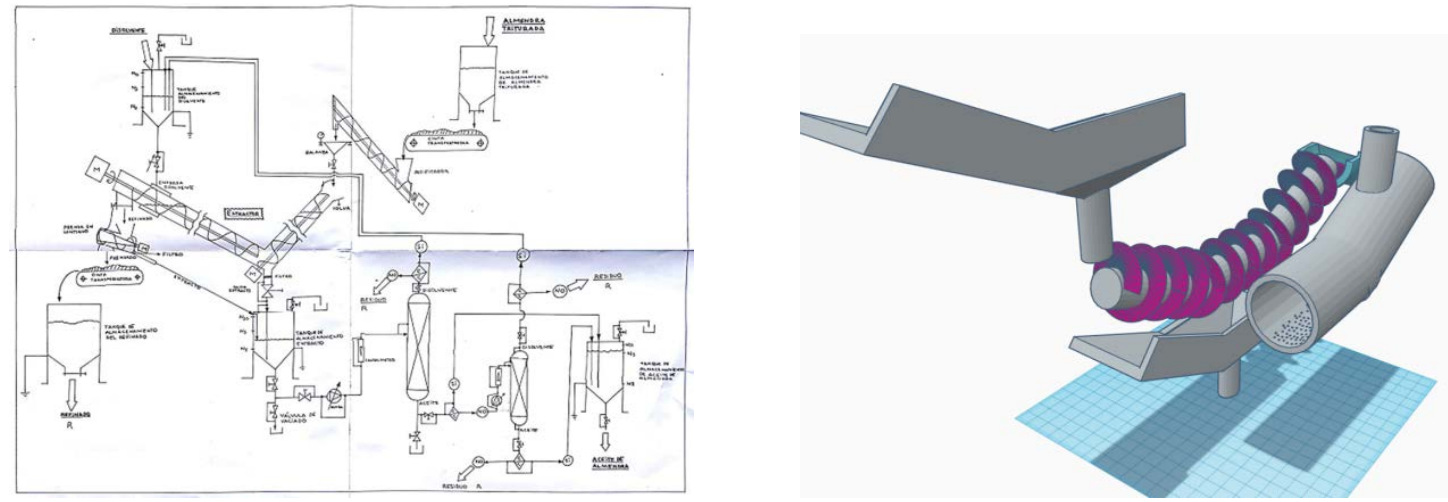

Figure 1. Example of the flow diagram of the solid-liquid extraction installation and example of a solid-liquid extractor design performed by the students of Elq3

Final mark of the design block is composed by the deliverables of the academic works (one for each laboratory session) which has a $28.6 \%$ of the final mark, design project $(57.2 \%)$ and a written exam $14.2 \%$.

In the following semester, students of PIIQ (that took the Elq3 subject in the previous semester) study different production processes and design a process to obtain olive oil. This design includes drawing of block and flow diagram of the full process in Autocad, selection and justification of safety measures needed and its implementation in the installation through its drawing in the flow diagram. An example of the design performed by the PIIQ students is shown in Figure 2.

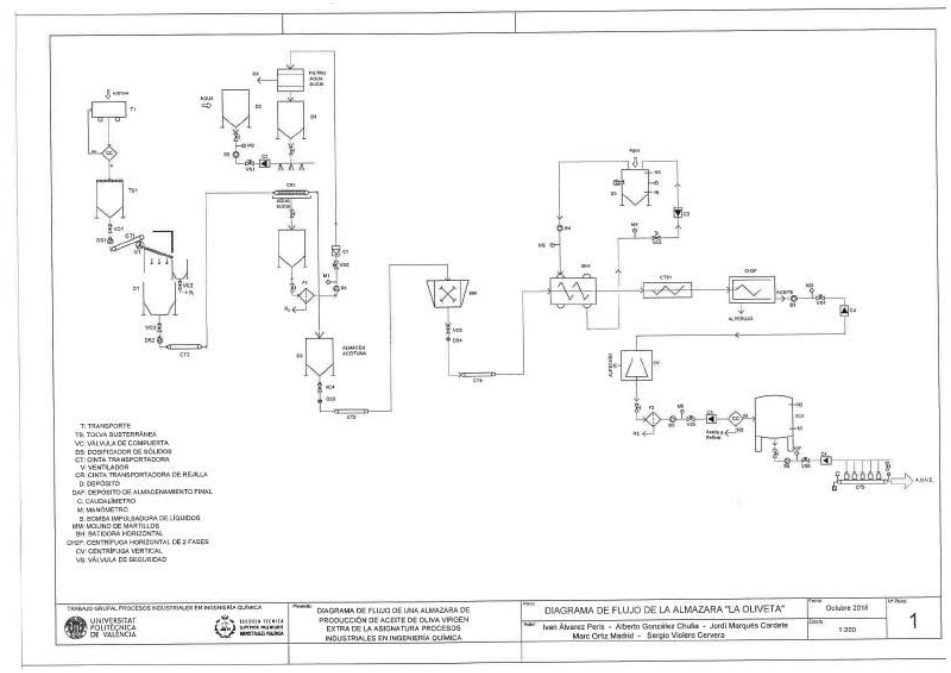

Figure 2. Example of the Flow diagram performed by the students in PIIQ

Safety is also strengthened in this subject through an activity of safety presentation about an item related to the solid-liquid extraction installation that students should prepare and defense through and oral presentation.

For assessment, students deliver the block and flow diagram of the industrial process in Autocad which represents $20 \%$ of the final mark of the subject and an oral presentation about safety which represents a $10 \%$ of the final mark of the subject.

Previously to these changes in Elq3 (that had a direct influence on PIIQ), integrated approach of design skills using POL methodology was developed only in PIIQ. Students were asked to represent a very basic block and flow diagram of a simple installation that feeds a solid and a liquid to a tank, through several deliverables collected in a portfolio (academic years 2013-2014 to 2015-2016) and with only one deliverable and performing the design in class (academic years 2016-2017 and 20172018). Due to design was a small part of the course and students didn't have previous knowledge to develop a project design, results obtained were very far from the ones expected for a chemical engineer. 
Table 2 shows progressive introduction of design skills through on PIIQ and Elq3 along the academic years.

Table 2. Introduction of design skills through on PIIQ and Elq3

\begin{tabular}{|c|c|c|c|}
\hline EIQIII & $\mathbf{P I I Q}$ & Methodology for Design in PIIQ & Type of work \\
\hline & 2013-2014 & Portfolio of 3 deliverables & Basic flow diagram \\
\hline & 2014-2015 & Portfolio of 3 deliverables & Basic flow diagram \\
\hline & $2015-2016$ & Portfolio of 2 deliverables & Basic flow diagram \\
\hline & $2016-2017$ & $\begin{array}{l}\text { Project of } 1 \text { deliverable }+ \\
\text { supervision in class }\end{array}$ & $\begin{array}{l}\text { Flow diagram with Autocad } \\
\text { (recommended) }\end{array}$ \\
\hline $\begin{array}{l}2016-2017 \text { (starts } \\
\text { IPOL project) }\end{array}$ & $2017-2018$ & $\begin{array}{l}\text { Project of } 1 \text { deliverable + } \\
\text { supervision in class }\end{array}$ & $\begin{array}{l}\text { Project of block and flow diagram } \\
\text { with Autocad (required) }\end{array}$ \\
\hline
\end{tabular}

This work will analyze the evolution of the level in the TC 5 (design and safety skills) through the work delivered (flow diagram) of PIIQ once IPOL has been implemented in the Elq3.

\section{RESULTS}

We will analyse the evolution of the learning level on design and safety skills acquired through EIQIII and PIIQ subjects, and the influence that the implementation of ISES and IPOL had over the results obtained in PIIQ. The analysis will be based on the comparison of the marks obtained in the different assessment control points stablished along both subjects. This control points are shown in Table 3.

Table 3. Control points to check level and evolution of design and safety skills along Elq3 and PIIQ courses

\begin{tabular}{|c|c|c|c|c|c|c|}
\hline \multirow[b]{3}{*}{$\begin{array}{l}\text { Control } \\
\text { point }\end{array}$} & \multicolumn{6}{|c|}{ Course } \\
\hline & \multicolumn{4}{|c|}{ Elq3, $3^{\text {rd }}$ course, semester B } & \multicolumn{2}{|c|}{ PIIQ, $4^{\text {th }}$ course, semester $A$} \\
\hline & $\begin{array}{l}\text { Deliverable of } \\
\text { safety seminar }\end{array}$ & $\begin{array}{l}\text { Deliverable of design } \\
\text { (S-L extraction block } \\
\text { diagram) }\end{array}$ & $\begin{array}{c}\text { Final project } \\
\text { (design and } \\
\text { safety) }\end{array}$ & $\begin{array}{l}\text { Written } \\
\text { exam }\end{array}$ & $\begin{array}{l}\text { Block and } \\
\text { flow } \\
\text { diagram }\end{array}$ & $\begin{array}{c}\text { Safety } \\
\text { presentation }\end{array}$ \\
\hline When & $\begin{array}{l}\text { Beginning of } \\
\text { semester }\end{array}$ & Beginning of semester & $\begin{array}{l}\text { End of } \\
\text { semester }\end{array}$ & $\begin{array}{l}\text { End of } \\
\text { semester }\end{array}$ & $\begin{array}{l}\text { End of } \\
\text { semester }\end{array}$ & End of semester \\
\hline
\end{tabular}

\subsection{Evolution of safety and design skills in PIIQ course}

First it will be shown in Table 4, average results of Safety and Design skills in the PIIQ course, comparing the first academic years (where the pedagogical innovation projects were not performed or performed partially) and the present academic year.

Table 4. Comparison of design and safety skills assessment in PIIQ

\begin{tabular}{ccccc}
\hline $\begin{array}{c}\text { Academic } \\
\text { year }\end{array}$ & $\begin{array}{c}\text { Design skill } \\
\text { (average mark) }\end{array}$ & $\begin{array}{c}\text { Safety skill } \\
\text { (average mark) }\end{array}$ & ISES Project started & $\begin{array}{c}\text { IPOL Project } \\
\text { started }\end{array}$ \\
\hline $2013-2014$ & 6.5 & 5.6 & Yes (only in Elq3) & No \\
$2014-2015$ & 6.0 & 5.4 & Yes (in Elq2 and Elq3) & No \\
$2015-2016$ & 5.4 & 8.4 & Yes ((in Elq1, Elq2 and Elq3) & No \\
$2018-2019$ & 9.0 & 8.8 & Yes (in Elq1,2 and 3) & Yes (in Elq3) \\
\hline
\end{tabular}

As it can be seen, initial level of the students on design and safety skills assessed through academic works performed in PIIQ was quite low reaching average marks of 6.5 over 10 in design and 5.6 over 10 in safety in academic year 2013-2014. In this year, students attending PIIQ, had no previous training on design skills and very basic skills of safety acquired through ISES project implemented only 
in Elq3. In 2014-2015, results of design and safety skills are similar to ones obtained in 2013-2014, even students of PIIQ of this academic year have received more training in safety than the ones of 2013-2014, because ISES project was implemented in EIQ2 and EIQ3. In 2015-2016, there is a significant improvement observed in safety skills because average mark goes from 5.4 to 8.4. This situation can be explained because students of PIIQ year have attended to Elq1, 2 and 3 subjects where ISES project was implemented. So safety work done previously has a direct influence on the final level of the students at the end of the semester. The change of the methodology to work safety skills from guided classroom practice to case of study could also influence on the result. Design skills had the same result as previous academic year since no changes were developed in this area in both subjects.

After that, improvements were performed in this subject changing the methodology to work design skills. Results of the present academic year show that in the design skill results, the implementation of the IPOL project in Elq3 had a very positive influence in the results obtained Design skill mark of the students is, on average, 9 points over 10 which is the highest mark obtained in the historical data of the subject. In this result also has a direct influence the change of methodology to work design skills, proposing a project of installation design based on a process explained in the theoretical classes but supervised by the lecturer in class.

For safety skill results, improvement observed in the mark of the previous academic years is kept nowadays. It is clear that previous work on safety done in experimental subjects as a consequence of the implementation of the ISES project has a very positive influence on the level of skills acquired by the students.

\subsection{Evolution of safety and design skills in Elq3 course}

In order to analyze evolution of safety and design skills of the students we will take the data of 20172018 academic year which is the first were IPOL has been implemented simultaneously with ISES on Elq3 course. Table 5 shows the average marks obtained on the different evidences items of the assessment.

Table 5. Evolution of safety and design skills along Elq3 course

\begin{tabular}{ccccc}
\hline \multicolumn{5}{c}{ Elq3 (average marks) } \\
\hline $\begin{array}{c}\text { Academic } \\
\text { year }\end{array}$ & $\begin{array}{c}\text { Deliverable } \\
\text { of safety }\end{array}$ & $\begin{array}{c}\text { Deliverable of } \\
\text { design }\end{array}$ & $\begin{array}{c}\text { Design \& safety } \\
\text { Project }\end{array}$ & $\begin{array}{c}\text { Written } \\
\text { exam }\end{array}$ \\
\hline $\mathbf{2 0 1 7 - 2 0 1 8}$ & 7.9 & 8.1 & 8.6 & 8.5 \\
\hline
\end{tabular}

As we can see on Table 5, there is an improvement on the level of safety and design skills along the Elq3 subject. Average marks of safety and design obtained after the lab practice are lower than the marks obtained at the end of the subject at the final project and written exam. These results can be explained for the positive effect that application of innovative methodologies as a consequence of ISES and IPOL projects has on the students increasing their motivation, self-learning and troubleshooting ability. If we compare these results with the ones obtained at the end of PIIQ (20182019), we can see that the learning on safety and design skills reached in Elq3 is kept and improved in the medium term (6 months), allowing students (after attending to two consecutive courses where this skills are worked) to reach excellent results (nearly 9 over 10 in both aspects).

Finally, an analysis of marks distribution of each item of the assessment (safety deliverable, design deliverable, final project and final exam) is performed. Figure 3 shows the distribution of marks splitted into 4 ranges ( $<5$, from $5-7$, from 7 to $9,>9$ over 10 points). 


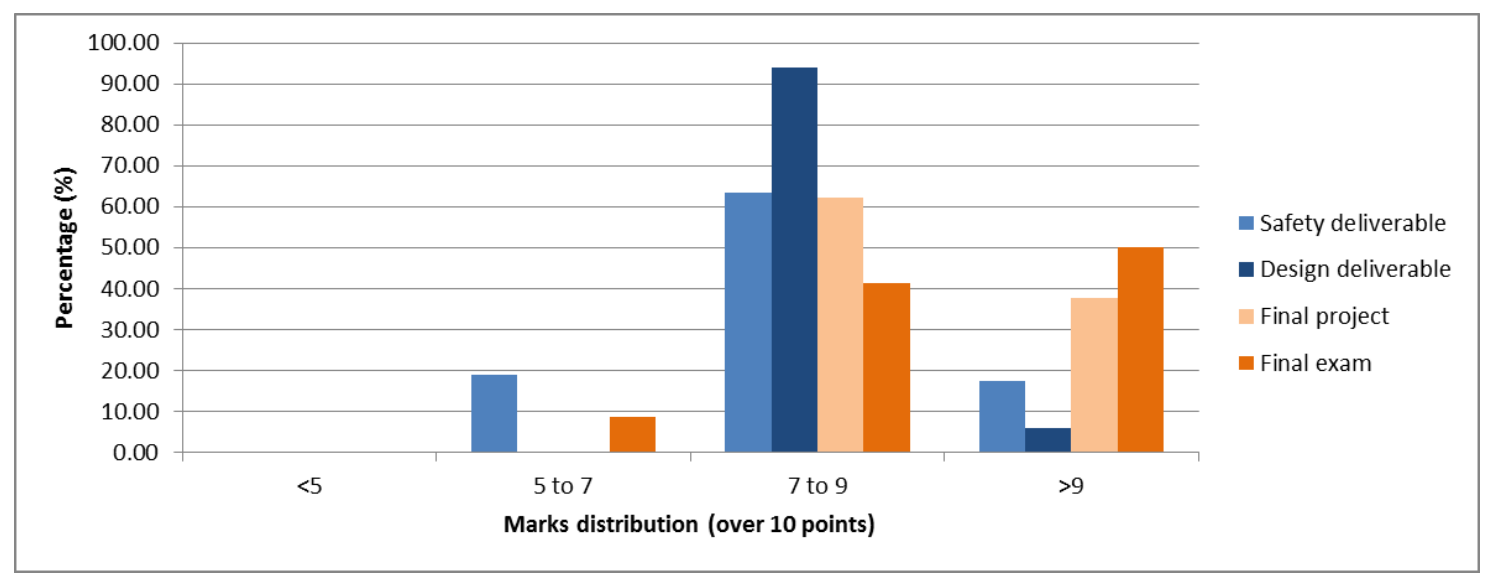

As it can be seen, safety and design deliverables (which have an average mark of 7.9 and 8.1 over 10), have a 60 and $90 \%$ of the marks in the range of 7 to 9 respectively and 15 and $5 \%$ of the marks in the range of $>9$. This deliverables are performed after the seminar and lab practice at the beginning of the semester. Along the semester the students work in parallel their design project, that is presented almost at the end of the semester, prior to the final exam. Average marks of the final project and final exam are 8.6 and 8.7 over 10 respectively. This increase in the final marks is accompanied of an increase in the percentage of marks in the $>9$ range, corresponding to 35 and $50 \%$ respectively. So, progressive work along the semester allows the increase of the learning level of the students in general but also the percentage of the students that reach excellent results on safety and design skills.

\section{CONCLUSIONS}

As a consequence of the analysis of learning level on design and safety skills of the students in Elq3 and PIIQ subjects of the Chemical engineering degree of the UPV it can be stated that:

- Safety and design skills are basic on chemical engineers training and for the development of their professional live.

- Implementation of innovative and more active methodologies helps to develop design and safety skills of the chemical engineering students

- Accommodation of the students to the new methodologies is needed as well as their motivation for the success of the methodological changes. Development of an engineer project based on experimental work and installations known would help to that.

- Coordinated and integrated work between subjects and different areas of the chemical engineers curriculum is needed to reach an accurate learning level on design and safety skills.

- Progressive work along two consecutive courses in safety and design skills have allowed to obtain a deeper degree of learning in these disciplines and better results in a medium term compared with the previous academic years in which these activities and methodology were not performed in both subjects.

\section{REFERENCES}

[1] M.J. Pitt. "Teaching safety in Chemical Engineering. What, How and Who?". Chemical Engineering and Technology. Vol. 35, issue 8, pp. 1341 (2012).

[2] D.C. Shallcross. "Safety shares in the chemical engineering classroom". Education for Chemical Engineers, Vol. 9, e94. (2014).

[3] R.M. Darbra; J. Casal; E. Pastor, J.A. Vilchez, J. Arnaldos, E. Planas. "Risk analysis active learning through the investigation of real cases". Process Safety and Environmental Protection. Vol. 90, pp. 430 (2012).

[4] T.A. Kletz, "Should undergraduates be instructed in loss prevention?". Plant and Operation Progress, Vol. 7, Issue. 2, pp. 95 (1988). 
[5] D.C. Hendershot, W. Smades. "Safety culture begins in the classroom" . Process Safety Progress, Vol. 26, Issue 2, pp. 83. (2007).

[6] Universitat Politècnica de València." Proyecto competencias transversales UPV". Avaliable at: https://www.upv.es/entidades/ICE/info/U0724624.pdf.

[7] B. García-Fayos, M. Sancho, J.M. Arnal (2016) "Teaching and learning industrial safety in chemical engineering: cooperative work based on the analysis of case studies of accidents in the chemical industry", INTED 2016 Proceedings, pp. 1182-1189.

[8] B. García-Fayos, M. Sancho, J.M. Arnal (2017) "Implementation of cooperative learning methodology in a compulsory course of the chemical engineering degree at the Universitat Politecnica de Valencia", INTED 2017 Proceedings, pp. 6422-6431.

[9] M. Sancho, B. García-Fayos, J. M. Arnal (2017) "Methodological change in an experimental subject of chemical engineering degree: project learning based on laboratory practice", INTED 2017 Proceedings, pp. 6390-6396. 